\title{
Rockfall impacts on sheltering tunnels: real-scale experiments
}

\author{
F. CALVETTI* and C. DI PRISCO*
}

In this paper the results of a series of rockfall impact tests on a sheltering tunnel are discussed. A reinforcedconcrete (RC) sphere (mass $850 \mathrm{~kg}$, diameter $0.9 \mathrm{~m}$ ) was dropped (falling height ranging between $5 \mathrm{~m}$ and $45 \mathrm{~m}$ ) on a tunnel along a road in the Dolomites. This experimental programme represents the extension of a previous one, performed at Politecnico di Milano (Campus Bovisa), when the same RC sphere was dropped on a circular pool filled with a loose sand stratum. The new programme is characterised by larger falling heights and the monitoring of the mechanical response of the shelter. A series of instruments have been employed to measure impact forces, stress propagation within the absorbing soil stratum on top of the shelter, and its deflection. The results, which are in good agreement with available literature data, are presented with the aim of highlighting the features of the complex impact event and discussing the engineering factors to be considered for conceiving a realistic and reliable design approach. The main conclusion is that the impact force is unaffected by the presence of the plate, and that the stress increment on the structure is slightly reduced by the structure deflection, which can be neglected for design purposes without unreasonable levels of conservatism being introduced.

KEYWORDS: design; full-scale tests; landslides; soil/structure interaction; tunnels
Dans la présente communication, on se penche sur les résultats d'une série d'essais sur les impacts de chutes de roches sur un tunnel d'abri. Pour ceci, on a fait tomber une sphère en béton armé, d'une masse de $850 \mathrm{~kg}$ et de $90 \mathrm{~cm}$ de diamètre, d'une hauteur allant de 5 à 45 mètres, sur un tunnel situé sur une route dans les Dolomites. Cette campagne d'expériences constitue l'extension d'une campagne précédente, menée à l'institut Politecnico di Milano (Campus Bovisa), au cours de laquelle on fit tomber cette même sphère en béton armé sur une piscine circulaire remplie d'une couche de sable libre. Au-delà des différences évoquées, la nouvelle campagne est caractérisée par des hauteurs de chute majeures, ainsi que par le contrôle de la réponse mécanique de l'abri. On a utilisé une série d'instruments pour mesurer les forces d'impact, la propagation des contraintes au sein de la couche de sol absorbante sur le dessus de l'abri, et sa déflexion. Les résultats, qui s'accordent bien avec les informations contenues dans des ouvrages disponibles, sont présentés dans le but de mettre en lumière les caractéristiques de l'impact complexe et de discuter des facteurs techniques devant être examinés pour la conception d'une méthode d'étude à la fois réaliste et fiable. En ce qui concerne ce dernier point, la principale conclusion que l'on en tire est que la force d'impact n'est pas affectée par la présence de la plaque, et que l'augmentation des contraintes sur a structure est légèrement atténuée par la déflexion de la structure, dont on peut ne pas tenir compte aux fins de l'étude sas introduire pour cela des niveaux de conservatisme excessifs.

\section{INTRODUCTION}

Rockfall events are complex phenomena characterised by several phases, including triggering/detachment, propagation (falling trajectories), and impacts on structures or shelters. The study of these separate phases requires specific methods and models to be defined, and a statistic approach is typically employed to cope with uncertainties affecting the problem, typically as far as the propagation phase is concerned.

In this paper the specific problem of the impact of blocks on tunnels covered by granular dissipative cushions is considered. A relatively small amount of data is available in the scientific literature with reference to this problem, and therefore the design of these structures is still based on quite strong simplifying hypotheses regarding both dynamic actions arising during impacts and the stress distribution transmitted to the structure. For instance, despite the impact of falling rocks being clearly a dynamic process, design guidelines and handbooks issued in Switzerland (ASTRA, 2008) and Japan (JRA, 2000) focus on the definition of static equivalent forces.

Manuscript received 24 March 2009; revised manuscript accepted 28 February 2012.

Discussion on this paper is welcomed by the editor.

* Politecnico di Milano, Dipartimento di Ingegneria Strutturale, Milano, Italy
The typical test for rockfall shelters consists of dropping rock or concrete blocks from a given height, and measuring the block acceleration, the vertical stresses within the soil stratum and the structural response. This allows the evaluation of impact forces, the diffusion and propagation of stresses within the soil and the response of the structure. Based on the results of this type of experiment, new design approaches that take the dynamic nature of the phenomenon into consideration were recently proposed by Calvetti \& di Prisco $(2010,2011)$ and Schellenberg \& Vogel (2009).

In order to summarise the main features of rockfall impacts, it is useful to refer to the concepts introduced by Labiouse et al. $(1994,1996)$ with reference to the results of a well-documented programme. In this programme three concrete blocks (masses $100 \mathrm{~kg}, 500 \mathrm{~kg}$ and $1000 \mathrm{~kg}$ ) were dropped vertically on a soil stratum covering a reinforcedconcrete (RC) plate $(3.4 \mathrm{~m} \times 3.4 \mathrm{~m} \times 2 \mathrm{~m})$. The falling height and absorbing cushion thickness varied in the ranges $1-10 \mathrm{~m}$ and $0 \cdot 25-1 \mathrm{~m}$ respectively.

In the papers by Labiouse et al. (1994, 1996), attention was focused on three different aspects (see Fig. 1)

(a) impact/penetration of the block on the surface of the soil stratum

(b) stress increments recorded at the interface between the soil and the upper face of the plate

(c) the structural response (plate deflection and support reaction). 


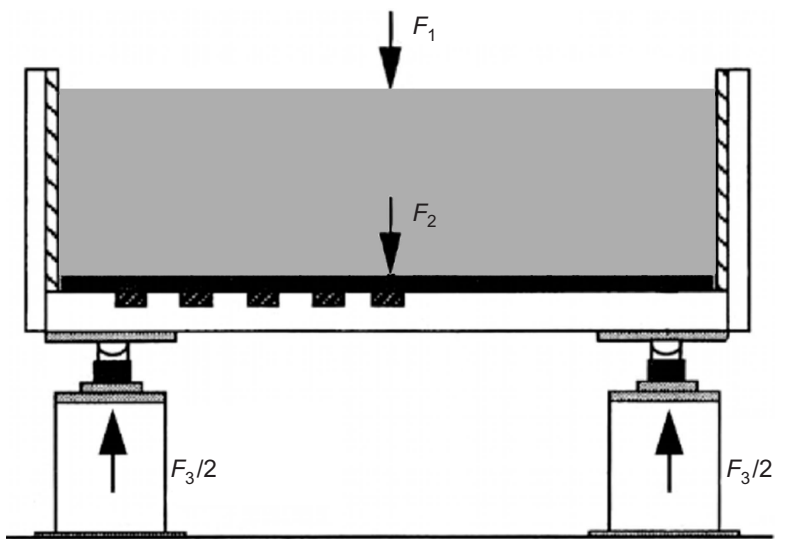

Fig. 1. Schematic representation of impact actions: $F_{1}$, impact force; $F_{2}$, resultant of stress increments on plate; $F_{3}$, support reaction (modified after Labiouse et al., 1994)

Analysis of the characteristic forces (Fig. 1) reveals that the maximum values for $F_{1}, F_{2}$ and $F_{3}$ are recorded at three subsequent instants of time $\left(t_{1 \max }<t_{2 \max }<t_{3 \max }\right)$, that the maximum values are different and, for the conditions investigated, $F_{1 \max }<F_{2 \max }<\mathrm{F}_{3 \max }$. (In static conditions, it would obviously be $F_{1}=F_{2}=F_{3}$.)

A series of similar experiments have recently been performed at Politecnico di Milano, Campus Bovisa (Calvetti et al., 2005). During these tests, an RC block (mass $850 \mathrm{~kg}$, diameter $0.9 \mathrm{~m}$ ) was dropped on a loose sand stratum covering a rigid concrete plate embedded in the ground. With respect to the tests by Labiouse et al. (1994, 1996), larger falling heights and impact energies were investigated. However, in such tests it was not possible to investigate any structural response, as the thickness of the bottom plate thickness was very large, and the plate itself was completely embedded in the ground.

\section{EXPERIMENTAL PROGRAMME}

The test described here represents a natural extension of the Campus Bovisa campaign, since larger impact energies were attained, and impacts took place on a real sheltering structure.

\section{Description of shelter}

The tested tunnel (Fig. 2) is located along a regional road in the Dolomites (Listolade, Belluno province). This shelter was designed in the late 1970s, and was initially used as an avalanche shelter. Subsequently, the shelter was covered with a layer of soil in an attempt to retrofit it for rockfall risk mitigation.

The top of the shelter consists of a $300 \mathrm{~mm}$ thick RC plate resting on a series of girders (prestressed I-beams: span $11.7 \mathrm{~m}$, spacing $1 \mathrm{~m}$ ). In turn, the plate rests on a supporting structure composed of a retaining wall and a series of portals, on the mountain and valley sides respectively (Fig. 2(b)).

The heterogeneous soil made of debris above the shelter has a grain-size distribution typical of coarse sand, within which several irregular blocks are included.

Some preliminary works were necessary before testing, owing to the lack of maintenance of the shelter (Fig. 3). First, the vegetation and larger blocks were removed from the surface of the soil stratum. Two trenches were excavated, with the aim of sampling the $\mathrm{RC}$ concrete plate and placing the load cells on the plate (Fig. 4(a)). Then the excavations were filled, and the granular stratum was levelled to obtain a constant $2 \mathrm{~m}$ thickness. Subsequently, in the area selected for impacts, the soil was compacted (Fig. 4(b)). After completion of the preliminary works, static standard plate tests were performed in the impact area. The measured values for $M_{\mathrm{E}}$ (see Table 1) were quite repeatable, which shows that the soil stratum was homogeneous. As will be shown below, this evidence was confirmed during impact tests; in fact, similar impact forces were recorded for similar impacts occurring at different locations.
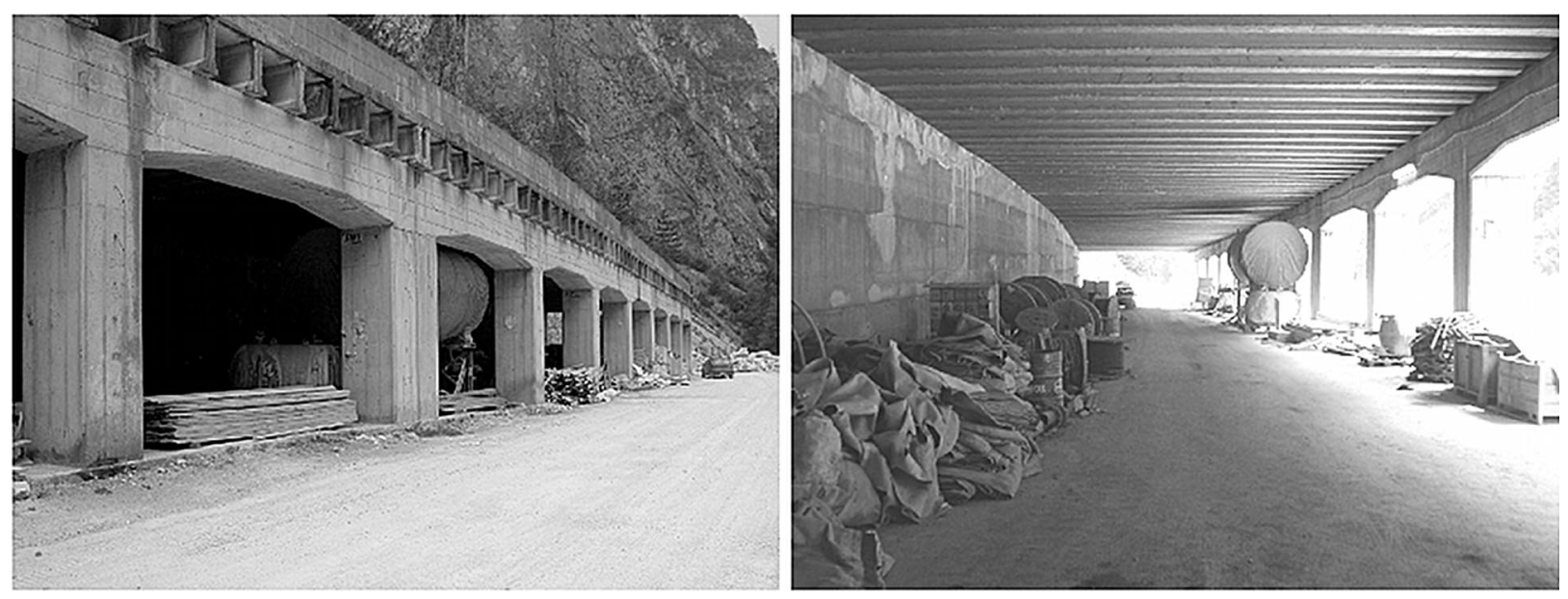

(a)
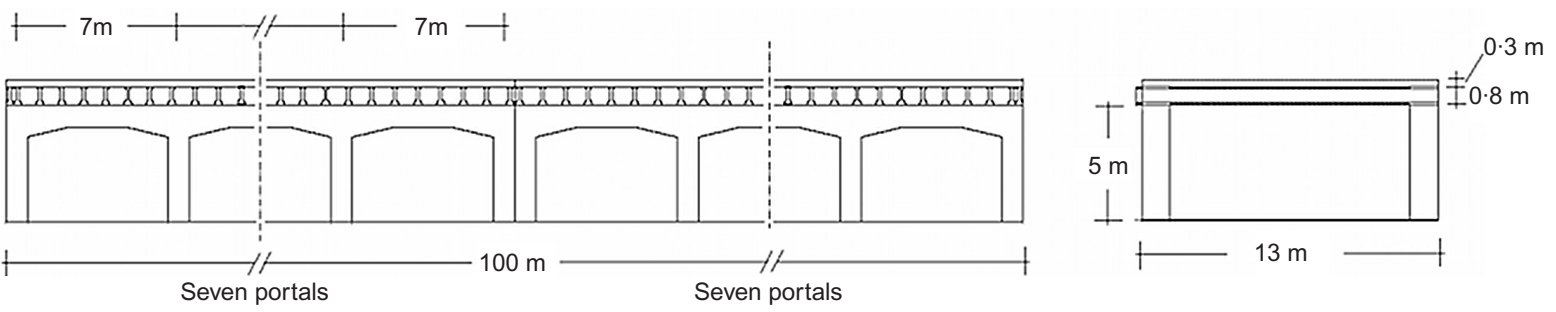

(b)

Fig. 2. (a) Lateral and internal views of shelter; (b) structural sketch with main dimensions (soil stratum not shown) 


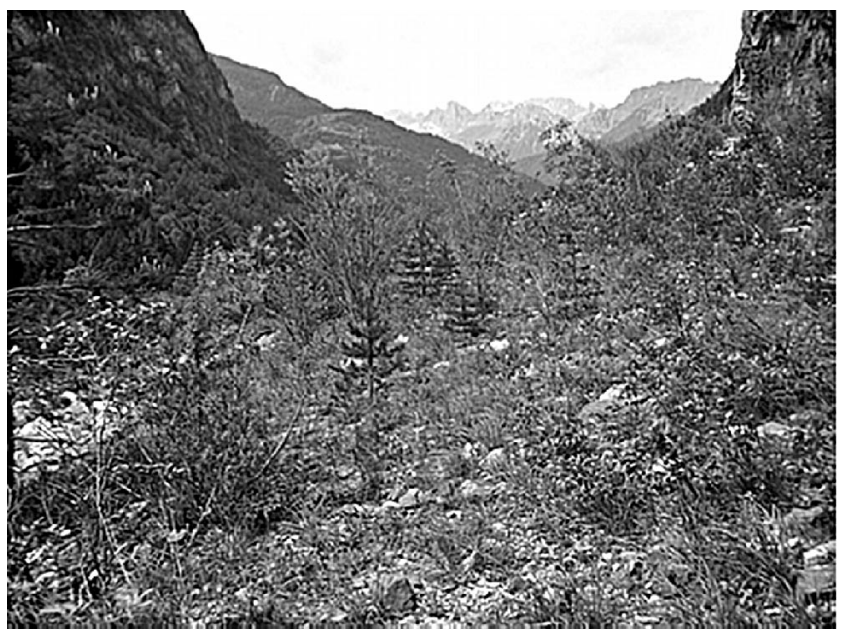

(a)

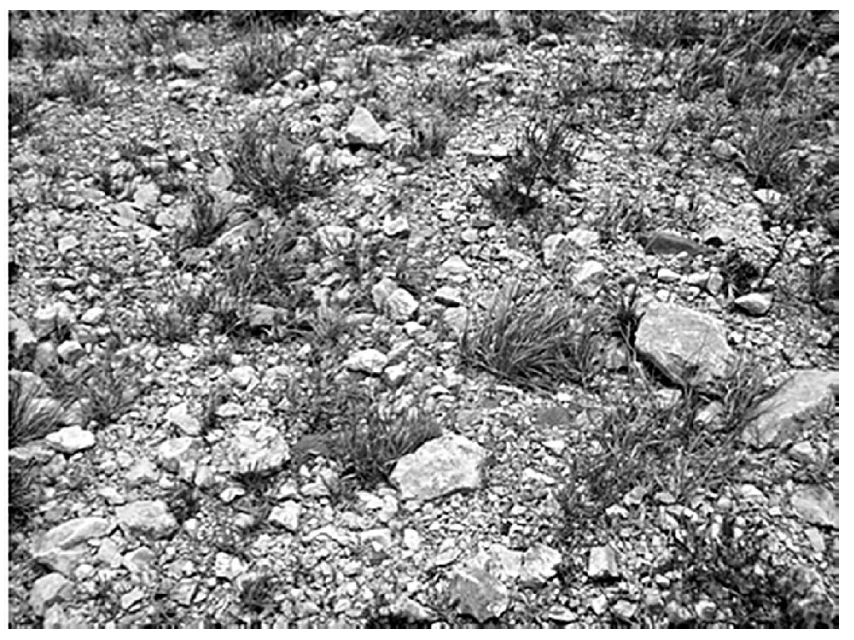

(b)

Fig. 3. Initial conditions of absorbing stratum: (a) general view; (b) close-up of the surface

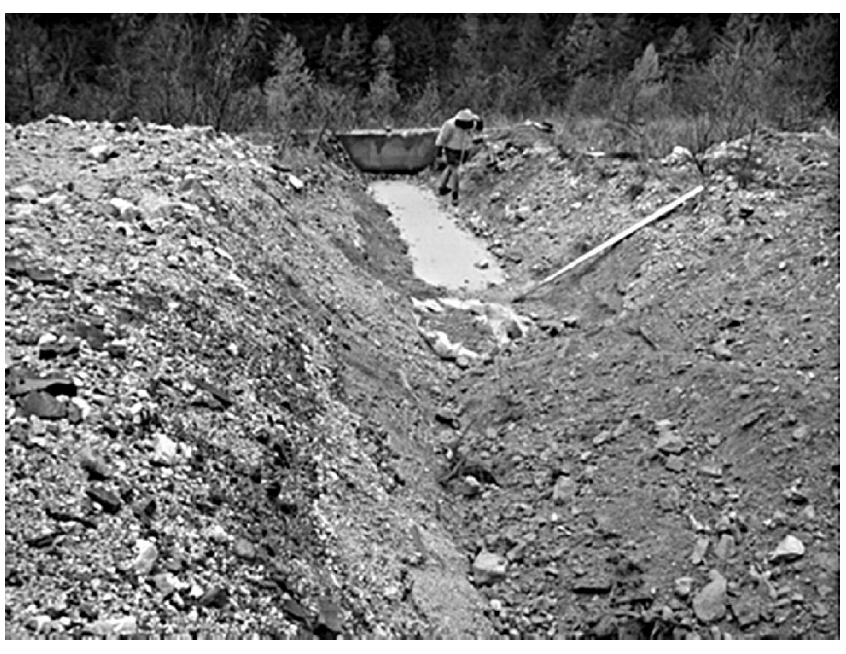

(a)

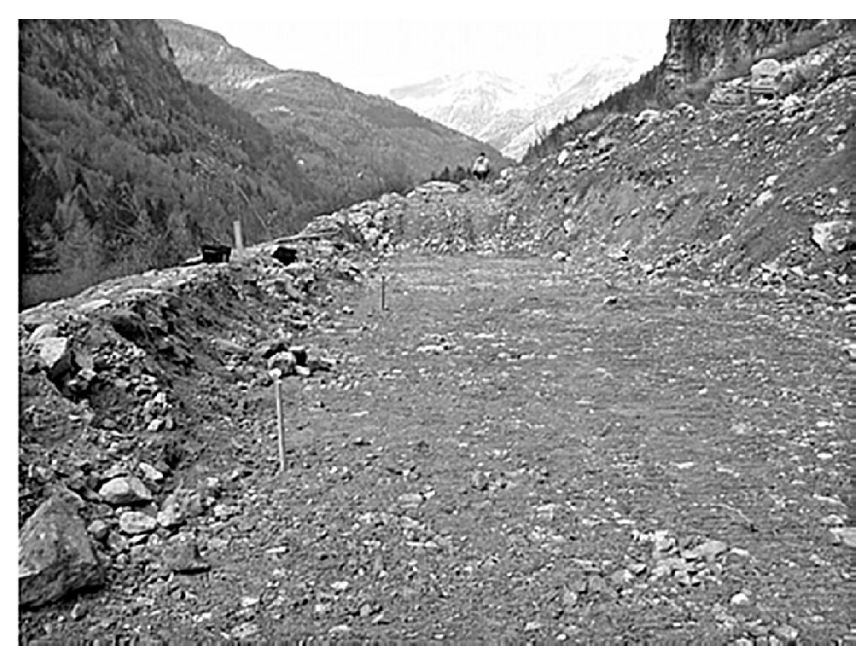

(b)

Fig. 4. Preparation of impact area: (a) trench excavation; (b) compacted impact area

Table 1. Mechanical parameters of soil layers tested at Listolade (dense sand) and Bovisa Campus (loose sand).

\begin{tabular}{l|c|c}
\hline & Loose sand & Dense sand \\
\hline Relative density, $D_{\mathrm{r}}: \%$ & 30 & 90 \\
Unit weight: $\mathrm{kN} / \mathrm{m}^{3}$ & 15 & 18 \\
Friction angle: degrees & 30 & 36 \\
Stiffness parameters, $K-n$ (Janbu, 1963): & $300-0 \cdot 45$ & $550-0 \cdot 4$ \\
dimensionless & - & 185 \\
$M_{\mathrm{E}}$, plate load test: $\mathrm{MPa}$ & - & \\
\hline
\end{tabular}

\section{Experimental programme}

The impacts were performed with the same block as used at Campus Bovisa (Calvetti et al., 2005), but the use of a telescopic jib crane made it possible to operate greater falling heights, in the range 5-45 $\mathrm{m}$ (impact energies in the range $40-375 \mathrm{~kJ})$.

A series of measurement devices were used to monitor impacts, as listed below.

(a) One accelerometer (Entran EGCS-250, range $\pm 250 \mathrm{~g}$ ) was embedded in the RC sphere. The recorded acceleration has been integrated to obtain the speed and position (penetration) of the block, and used directly to obtain the vertical inertia force acting on the block. (The impact force is the sum of the block inertia force and block weight.) For the investigated impacts, considering that decelerations as large as $200 \mathrm{~g}$ are typically observed, impact force is therefore virtually coincident with the block inertia force.

(b) Two load cells were placed on the shelter plate; they were used to evaluate the stress increment acting on the upper side of the plate. The two load cells were very close to each other (point A in Fig. 5) - virtually in the same position - in order to quantify the measurement scattering. This was typically less than $5 \%$ of the readings; in the following, all data refer to average values.

(c) Four LVDTs (linear variable differential transformers: Penny \& Giles SLS190, range $0-50 \mathrm{~mm}$, precision $\pm 0 \cdot 15 \%$ ) were located underneath the plate/girder (points $\mathrm{A}$ and $\mathrm{B}$ in Fig. 5) in order to measure its deflection.

(d) Two accelerometers (Entran EGCS-50, range $\pm 50 \mathrm{~g}$ ) were located underneath one girder (point A) and secured to the supporting elements (pillars and beam of the portal) respectively.

The tests performed during the experimental programme and the positions of the impact points are reported in Table 2 and Fig. 5 respectively. The impact tests can be systematically separated into three series. 


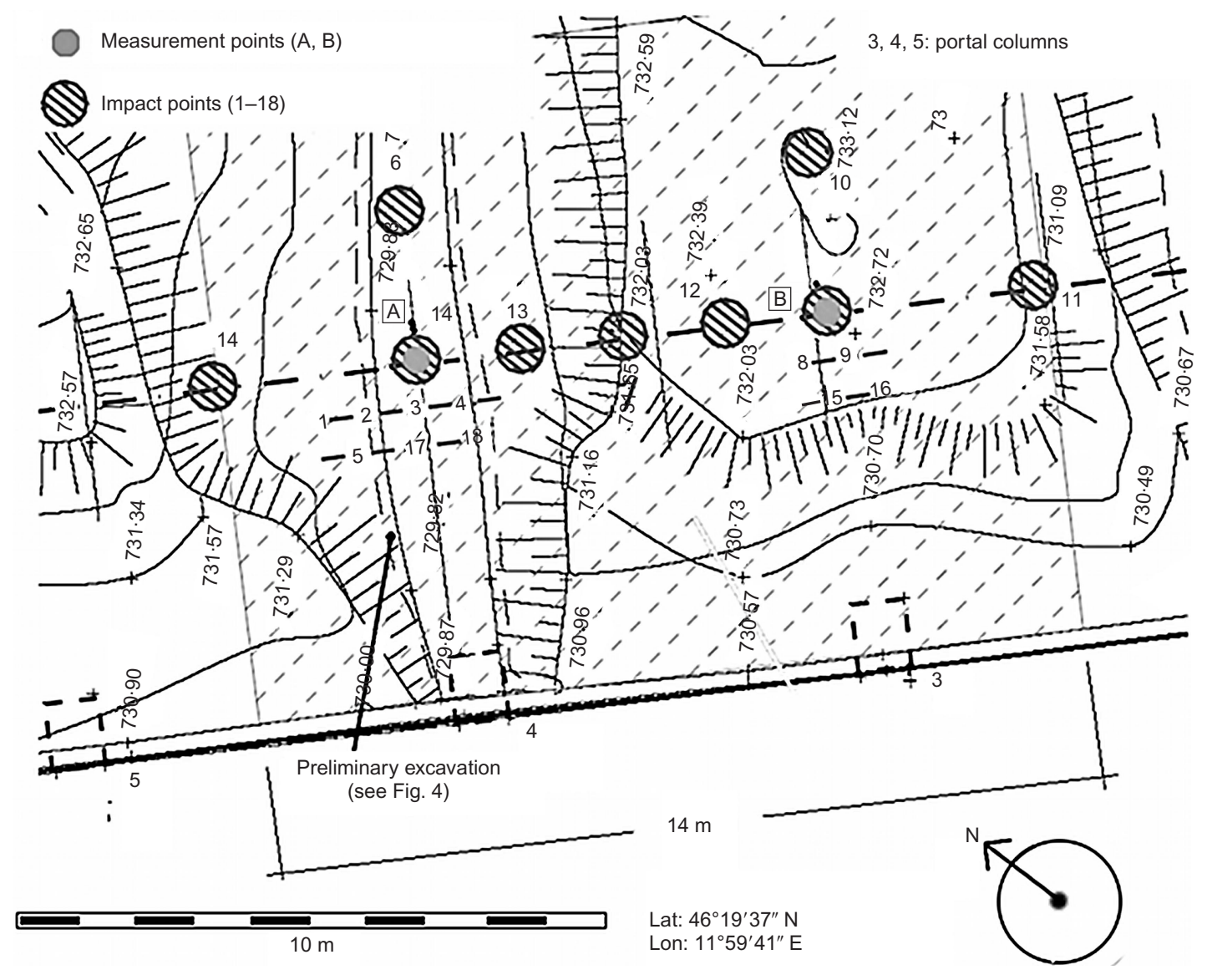

Fig. 5. Impact area: plan view

Table 2. Summary of the tests performed

\begin{tabular}{l|c|c|c|c|c|l}
\hline Test no. & Falling height: $\mathrm{m}$ & Impact energy: $\mathrm{kJ}$ & $F_{\max }: \mathrm{kN}$ & $r_{\mathrm{A}}: \mathrm{m}$ & $r_{\mathrm{B}}: \mathrm{m}$ & $r_{\mathrm{t}}: \mathrm{m}$ \\
\hline 1 & $6 \cdot 3$ & $52 \cdot 5$ & $549 \cdot 9$ & 0 & 7 & 0 \\
2 & $4 \cdot 9$ & $40 \cdot 8$ & $493 \cdot 5$ & 0 & 7 & 0 \\
3 & $8 \cdot 6$ & $71 \cdot 6$ & $643 \cdot 4$ & 0 & 7 & 0 \\
4 & $19 \cdot 4$ & $161 \cdot 6$ & $1047 \cdot 9$ & 0 & 7 & 0 \\
5 & $36 \cdot 4$ & $303 \cdot 2$ & $1728 \cdot 1$ & 0 & 7 & 0 \\
6 & $38 \cdot 6$ & $321 \cdot 5$ & $1311 \cdot 6$ & 0 & 7 & $2 \cdot 75$ \\
7 & $40 \cdot 0$ & $333 \cdot 2$ & $1943 \cdot 5$ & $3 \cdot 5$ & $3 \cdot 5$ & 0 \\
8 & $39 \cdot 9$ & $332 \cdot 4$ & $1687 \cdot 8$ & 7 & 0 & 0 \\
9 & $44 \cdot 8$ & $373 \cdot 2$ & $1584 \cdot 4$ & 7 & 0 & 0 \\
10 & $44 \cdot 8$ & $373 \cdot 2$ & $1617 \cdot 9$ & 7 & 0 & $2 \cdot 75$ \\
11 & $46 \cdot 3$ & $385 \cdot 7$ & $1855 \cdot 5$ & $10 \cdot 5$ & $3 \cdot 5$ & 0 \\
12 & $42 \cdot 2$ & $351 \cdot 5$ & $1624 \cdot 0$ & $5 \cdot 25$ & $1 \cdot 75$ & 0 \\
13 & $42 \cdot 3$ & $352 \cdot 4$ & $1655 \cdot 4$ & $1 \cdot 75$ & $5 \cdot 25$ & 0 \\
14 & $39 \cdot 6$ & $329 \cdot 9$ & $1778 \cdot 2$ & $3 \cdot 5$ & $10 \cdot 5$ & 0 \\
15 & $19 \cdot 3$ & $160 \cdot 8$ & $1616 \cdot 5$ & 7 & 0 & 0 \\
16 & $45 \cdot 4$ & $378 \cdot 2$ & - & 7 & 0 & 0 \\
17 & $15 \cdot 0$ & $125 \cdot 0$ & $1671 \cdot 3$ & 0 & 7 & 0 \\
18 & $42 \cdot 3$ & $352 \cdot 4$ & - & 0 & 7 & 0 \\
\hline
\end{tabular}

$r_{\mathrm{A}}$, distance from point $\mathrm{A}$ along tunnel axis; $r_{\mathrm{B}}$ : distance from point $\mathrm{B}$ along tunnel axis; $r_{\mathrm{t}}$ : distance from tunnel axis.

In order to study the influence of the falling height on the dynamic mechanical response of the system, impacts 1-5 were performed by keeping the impact position constant and increasing the falling height. After each impact, the impact crater was filled and compacted; this procedure, thanks to the high relative density of the soil, was observed to be effective in erasing the consequences of previous impacts. During the previous experimental programme (Campus Bovisa), where a loose sand stratum was tested, the compacting effects of impacts were much stronger and extended in depth (Calvetti et al., 2005).

Impacts 6-14 (second series) were characterised by large and almost constant impact energy: most impacts of this series took place along the longitudinal axis of the plate. Among them, a large number of impacts took place at points $\mathrm{A}$ and $\mathrm{B}$ of Fig. 5, where measurement devices were placed. The experimental test results concerning this series will be used below to study the stress propagation within the 
stratum, the interaction between the soil and the plate, and the structural response.

The third and last series of tests (impacts 15-18) made it possible to study the effects of previous impacts: for this purpose, after each impact the soil was not remoulded.

\section{EXPERIMENTAL RESULTS}

In order to describe the impact phenomenon, the presentation of the experimental results is organised as follows. First, the general features of one typical impact are illustrated and discussed. Then the maximum values of the recorded data (impact force, stress increment on the plate and plate deflection) are analysed, and the influence of falling height is shown. Finally, the test results are analysed more deeply, with the aim of highlighting the structural response and the soil-plate interaction.

\section{Description of a typical impact}

The results of a typical impact (test 5, falling height $36.4 \mathrm{~m}$ ) are discussed by focusing on the evolution of impact force with time (Fig. 6(b)), the stress increment recorded at the soil/plate interface under the impact point (Fig. 6(c)), and the plate displacement and velocity (Figs 6(d)-6(f)). In all figures, $t_{0}=0$ is the time instant when the falling block impacts on the surface of the soil stratum.

As is evident from Fig. 6, the timescale characterising the impact is very short. The peak value of the impact force is attained just $0.005 \mathrm{~s}$ after the block has impacted on the soil surface; the impact duration, estimated as the width of the time period over which a significant impact force is exerted (i.e. over which the block undergoes a significant deceleration), is about $0.05 \mathrm{~s}$. Note that the time duration of impacts performed on loose sands was twice as large (Calvetti et al., 2005). In both cases, the impact duration was observed to be almost constant with falling height.

The stress on the plate starts to increase about $0.01 \mathrm{~s}$ after $t_{0}$. This time lag is due to propagation of the compression wave generated by the impact itself. Since the soil stratum is $2 \mathrm{~m}$ thick, this corresponds to a wave velocity of about 250 $300 \mathrm{~m} / \mathrm{s}$. For reference, a time lag twice as large was observed on a loose sand layer of similar height (the mechanical properties of both materials are reported in Table 1).

The time duration of the impulse recorded on the plate is about $0.05 \mathrm{~s}$ (Fig. 6(c)), a value similar to the impact duration. An important observation is that the maximum value of the block deceleration is attained before the impact wave has reached the plate (Figs 6(b) and 6(c)). This implies that the near-field block-surface interaction mechanism is unaffected by the presence of the underlying plate. This evidence, in agreement with the experimental and numerical results presented by Calvetti et al. (2005), is valid unless the thickness of the soil is less than about $1 \mathrm{~m}$.

The deflection of the plate is characterised by a first (forced) oscillation followed by damped free oscillations, the period of which can be approximately estimated as $0.15 \mathrm{~s}$, while the maximum deflection is attained for $t=0.04 \mathrm{~s}$ (Figs 6(d) and 6(f)). This means that the stress impulse is considerably shorter than the natural period of oscillation of the plate (Figs 6(c) and 6(f)). It is also worth noting that the plate deflection begins just as the stress wavefront reaches the plate itself (Figs 6(c) and 6(d)), which influences the stress distribution recorded on the plate itself.

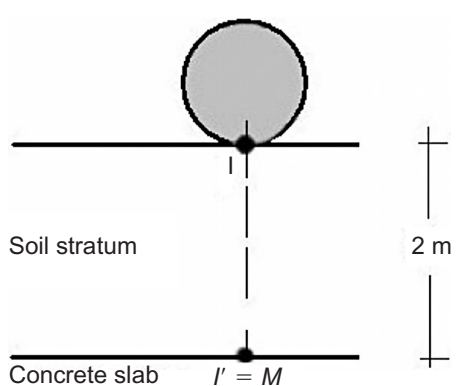

(a)

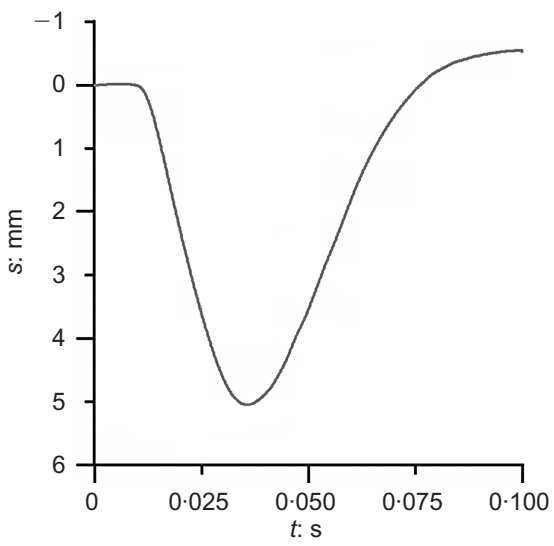

(d)

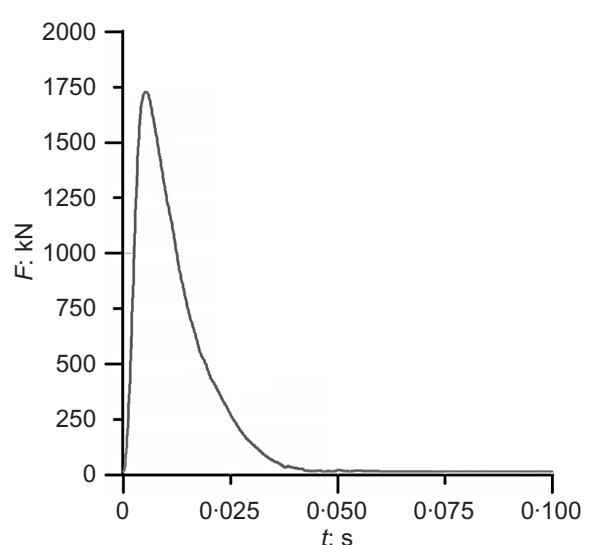

(b)

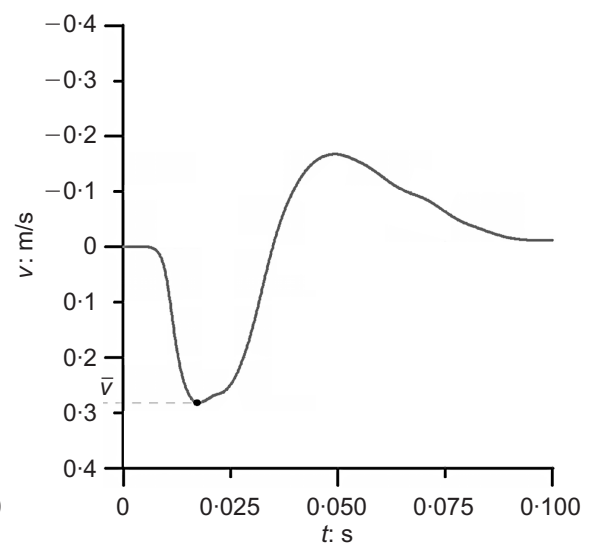

(e)

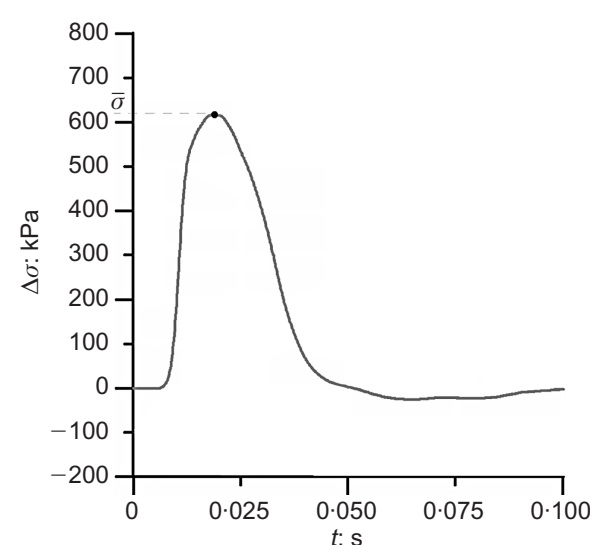

(c)

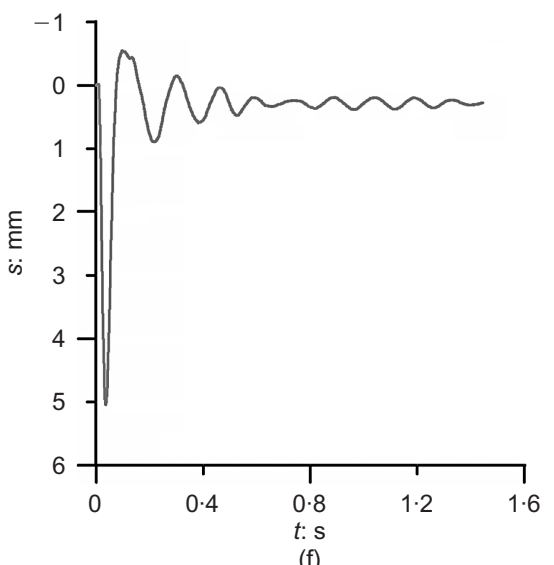

(f)

Fig. 6. Typical impact results (test $5, H=36.5 \mathrm{~m}$ ): (a) sketch of impact position; (b) impact force against time, $t$; (c) vertical stress increment recorded at $I^{\prime}$ against $t$; (d) plate deflection at $I^{\prime}$ against $t$ (first oscillation); (e) plate velocity at $I^{\prime}$ against $t$ (first oscillation); (f) plate deflection at $I^{\prime}$ against $t$ (extended observation period) 
In fact, the plate represents the lower boundary of the impact wave propagation domain. Although the stiffness of the plate material is considerably larger than that of the soil, structural deformability plays a role in affecting the pressures developing at the interface. In principle, a flexible plate represents an intermediate condition between a rigid boundary (complete reflection of the impact wave; stress amplification) and a free boundary (zero stress increment; displacements amplification).

Considering the maximum value of stress acting on the plate $(\bar{\sigma}$ in Fig. $6(\mathrm{c}))$, and the corresponding plate velocity $(\bar{v}$ in Fig. 6(e)), the point $R(\bar{v}, \bar{\sigma})$ of Fig. 7 is obtained. In this figure the theoretical correlation between boundary velocity $(v)$ and stress $(\sigma)$ is represented by a line passing through $R$ with a gradient defined as

$$
m=-\rho C
$$

where $\rho$ is the soil density, and $C$ is the propagation velocity of the stress wave. The intersection of the dashed line with the $v$-axis gives the velocity that would correspond to a free boundary $(\sigma=0)$, and its intersection with the $\sigma$-axis represents the stress that would be recorded on a fixed boundary $(v=0)$. The error introduced by assuming the boundary to be fixed, and by disregarding the coupling between the upper soil stratum and the underlying structure, can be therefore estimated as (see Fig. 7)

$$
\mathrm{ER}=\frac{\Delta \sigma}{\sigma^{\mathrm{RB}}}=\frac{\bar{v} \rho C}{\bar{\sigma}+\bar{v} \rho C}
$$

where $\Delta \sigma$ and $\sigma^{\mathrm{RB}}$ are defined in Fig. 7. In the case under investigation, $\rho=2000 \mathrm{~kg} / \mathrm{m}^{3}, C=250 \mathrm{~m} / \mathrm{s}, \quad \bar{v}=0.27 \mathrm{~m} / \mathrm{s}$, $\bar{\sigma}=600 \mathrm{kPa}$ and $\mathrm{ER}=18 \%$.

\section{Interpretation of results}

Maximum values of impact force, block penetration, stress increments. In Fig. 8, the maximum values of impact force recorded during each test are plotted against falling height, $H$. The results previously obtained at Campus Bovisa, derived from tests on a loose sand stratum, are also reported for comparison. The solid lines of Fig. 8 represent the correlation introduced by Labiouse et al. (1994)

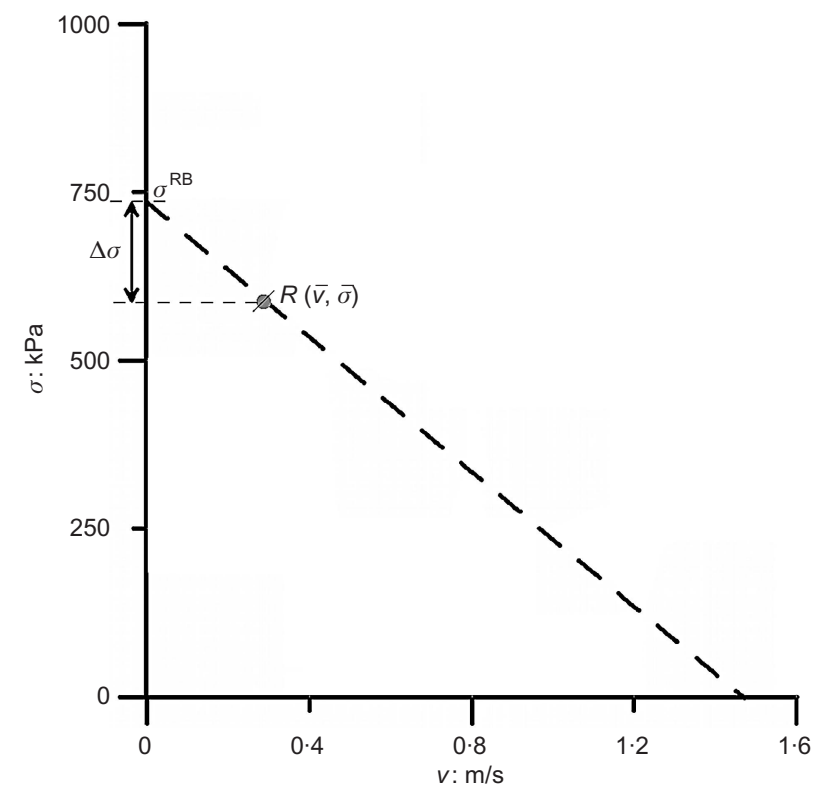

Fig. 7. Relation between boundary stress and boundary velocity

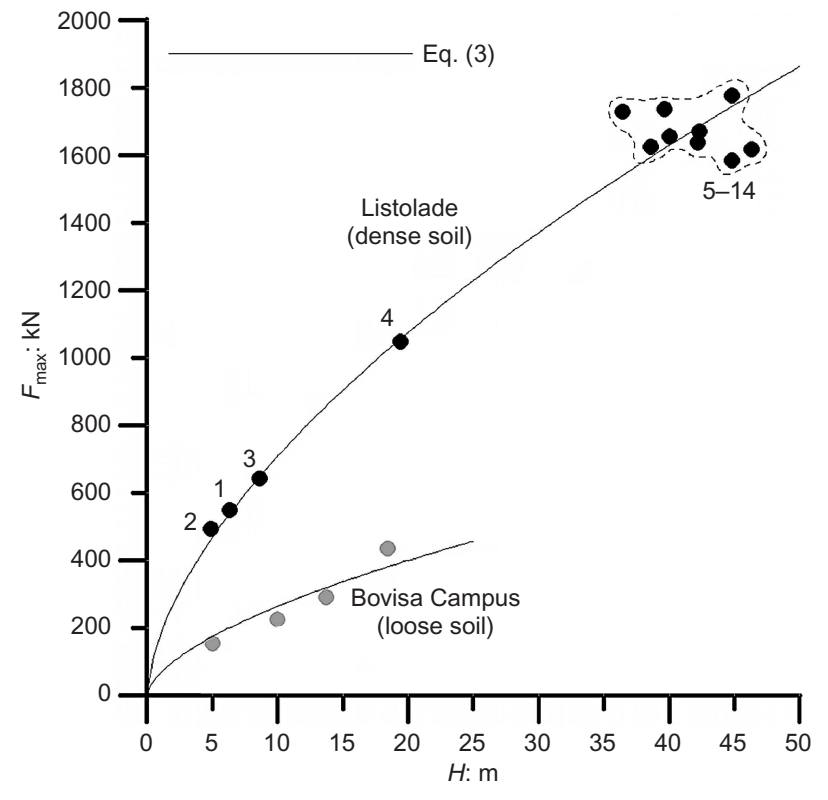

Fig. 8. Impact force as a function of falling height (labels refer to impact list of Table 2)

$$
F_{\max }=F_{0}\left(\frac{E}{E_{0}}\right)^{\alpha}=F_{0}\left(\frac{H}{H_{0}}\right)^{\alpha}
$$

where $F_{\max }$ is the maximum value of impact force, $E$ is impact energy and $H$ is falling height. Note that the mass of the falling block is the same for all the tests of Fig. 8. The terms with subscript 0 refer to reference values $\left(H_{0}=20 \mathrm{~m}\right.$; $\left.E_{0}=167 \mathrm{~kJ}\right)$. In order to interpolate the results, $F_{0}$ is set to $1075 \mathrm{kN}$ and $400 \mathrm{kN}$ for the dense and loose strata respectively, and $\alpha$ is equal to 0.6 in both cases. This latter value is the same as that initially suggested by Labiouse et al. (1994) and di Prisco \& Vecchiotti (2006) obtained similar values by using an elasto-viscoplastic rheological model for simulating the interaction between the impacting block and the granular stratum. Calvetti (1998) and Calvetti et al. (2005) used the same formula (with $\alpha=\frac{2}{3}$ ) in order to summarise the data obtained by performing distinct element numerical simulations of impact tests.

Many impacts were performed with a falling height of about $40 \mathrm{~m}$, at different impact locations along the shelter axis (see Table 2 and Fig. 5); the relative data scattering, which is likely to be due to the unavoidable residual heterogeneity of the stratum, seems quite acceptable. The results of these tests will be analysed in detail in the next section.

In Fig. 9 the relation between the block penetration and falling height is illustrated. Block penetration was obtained by direct inspection of the impact crater. The difference between these data and those obtained by double-integrating the block deceleration is less than $50 \mathrm{~mm}$ : that is, it is comparable with the scattering of the results themselves. The penetration depth barely exceeds $0.3 \mathrm{~m}$ for the highest impact energies, while during the tests performed on a loose sand stratum the penetration depth was much larger for the same impact energy. In both cases (loose and dense sand) no significant rebound was observed.

The results of Fig. 9 can be described by means of the relation (Calvetti \& di Prisco, 2007)

$$
d_{\max }=d_{0}\left(\frac{E}{E_{0}}\right)^{\beta}=d_{0}\left(\frac{H}{H_{0}}\right)^{\beta}
$$

where $d_{\max }$ is the block penetration, and the subscript 0 refers to reference values $\left(H_{0}=20 \mathrm{~m} ; E_{0}=167 \mathrm{~kJ}\right)$. In order to fit the results, $d_{0}$ is set to $0.225 \mathrm{~m}$ and $0.6 \mathrm{~m}$ for the 


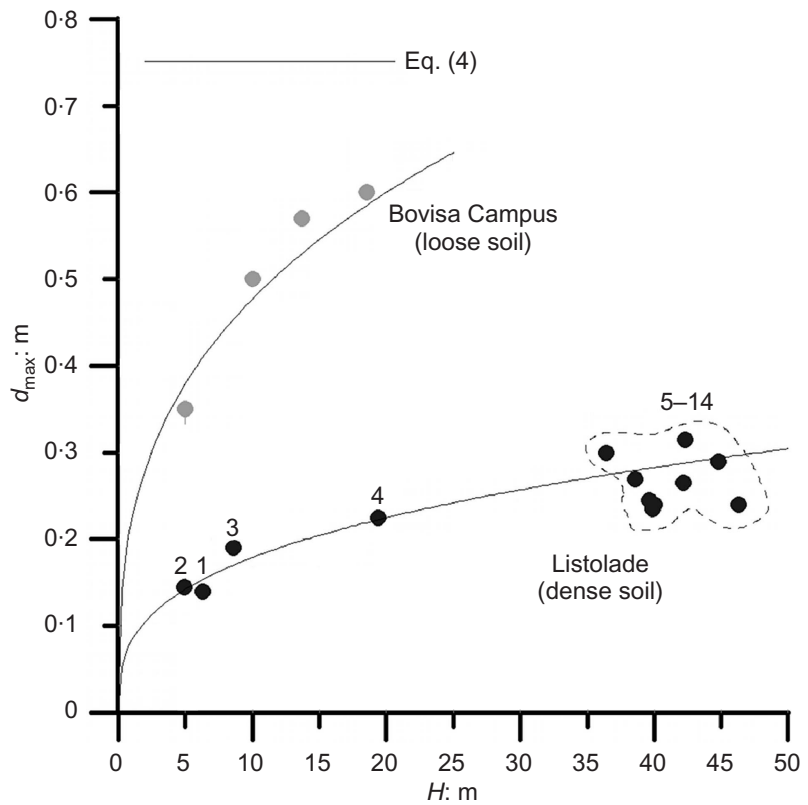

Fig. 9. Block penetration as a function of falling height (labels refer to impact list of Table 2)

dense and loose strata respectively; $\beta$ is equal to $\frac{1}{3}$ (for both conditions).

Impact force, stress propagation and structural response. By following the interpretation line proposed by Labiouse et al. (1994), a convenient way to study the progressive propagation of impact effects from the ground surface to the shelter consists in illustrating the relation between the maximum values of impact force $\left(F_{\max }\right)$, stress increment on the plate $\left(\Delta \sigma_{\max }\right)$ and plate deflection $\left(s_{\max }\right)$. All results reported in this paragraph correspond to impacts on virgin or remoulded soil; these impacts are characterised, as previously reported, by the same time duration, irrespective of falling height. The results belonging to the third series of tests (impacts on soil compacted by previous impacts) will be presented later in this paper.

In Fig. 10 (a) $\Delta \sigma_{\max }$ is plotted against $F_{\max }$; in Fig. 10(b) $s_{\max }$ is plotted against $\Delta \sigma_{\max }$. Note that the stratum thickness was $2 \mathrm{~m}$ for both dense and loose sand, which makes a meaningful comparison possible.

The experimental data of Fig. 10 show the existence of a clear linear relation between $\Delta \sigma_{\max }, F_{\max }$ and $s_{\max }$. This result is in agreement with previous observations by Labiouse et al. (1994) and Calvetti et al. (2005), although the comparison illustrated in Fig. 10(a) should be implemented with information regarding the spatial distribution of stress increments on the plate (not available for the impacts performed on a dense sand, where only one load cell was used).

By comparing the results obtained with loose and dense sand (Fig. 10(a)) it is clear that for a given $F_{\max }$ the stress increment on the plate is much larger for the loose stratum. This result cannot be explained if the dynamic nature of impact and stress propagation within the stratum is disregarded, and it suggests that a dynamic amplification factor should be introduced in order to describe quantitatively the correlation between $F_{\max }$ and $\Delta \sigma_{\max }$. This point has been further investigated by Calvetti \& di Prisco $(2007,2009)$ by means of finite difference analyses and spectral element analyses (Stupazzini \& Zambelli, 2005) of the wave propagation. The results of these analyses demonstrate that a dynamic amplification factor has to be introduced as a (decreasing) function of the soil stiffness.

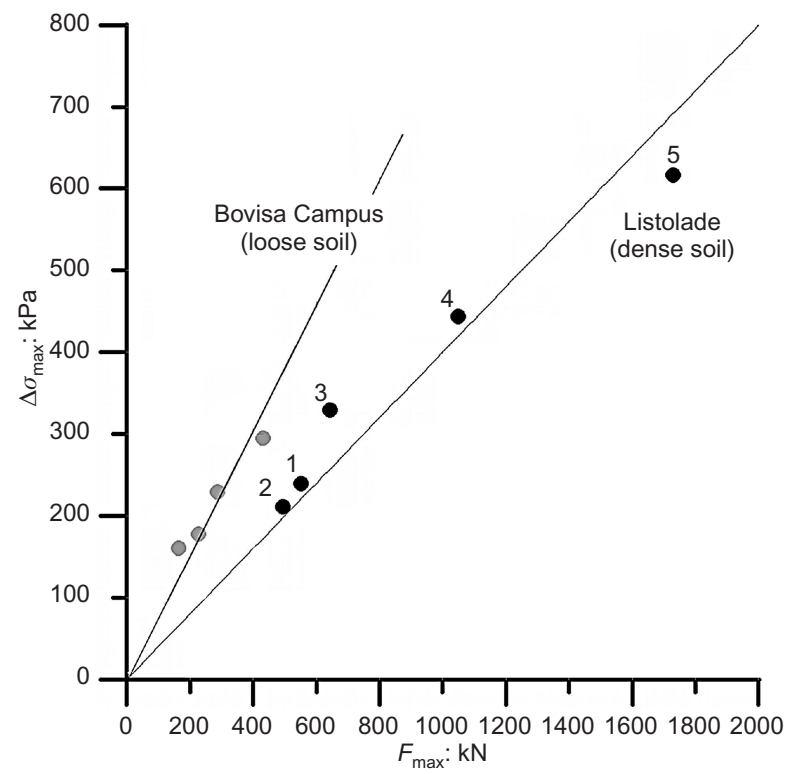

(a)

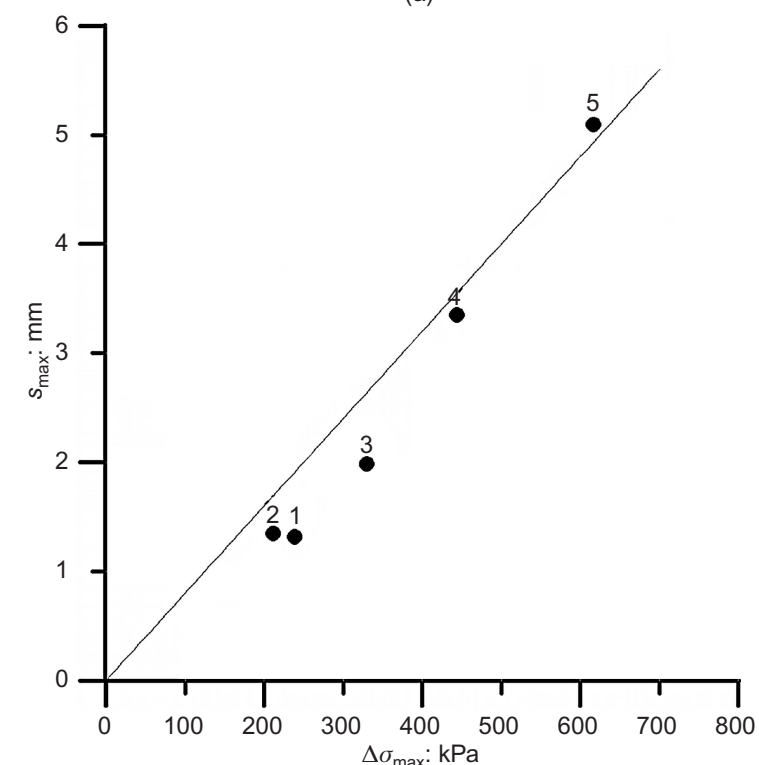

(b)

Fig. 10. (a) Maximum stress increment on plate against maximum impact force; (b) maximum plate deflection against maximum stress increment on plate (labels refer to impact list of Table 2)

\section{SOIL STRUCTURE INTERACTION AND STRUCTURAL RESPONSE}

In this section the experimental data are analysed further in order to study stress propagation within the soil stratum, soil-structure interaction, and structural behaviour.

As reported in Table 2, a large number of tests (impacts $9,10,11,12,13$ and 14) are characterised by similar falling heights $(43 \mathrm{~m} \pm 10 \%)$ and peak impact forces $(1650 \mathrm{kN}$ $\pm 10 \%$; see Fig. 8). Most of these impacts (all but no. 10) were performed along the longitudinal axis of the tunnel: therefore the results may conveniently be interpreted as a function of the distance, $r_{\mathrm{M}}$, from the points where the load cell and LVDTs are placed (points A and B in Fig. 5). This allows the structure deformation and its evolution with time to be evaluated. Additional information may be obtained from impact 10 which took place near point $\mathrm{B}$ at a quarter of the span, transversely with respect to the longitudinal axis (i.e. at $r_{\mathrm{t}}=2.75 \mathrm{~m}$ ). It is worth noting that the relevance of studying the deflection pattern in two orthogonal directions derives from the orthotropic structure of the roof. 


\section{Plate deflection}

In Figs 11(a)-11(e) the deflection of the plate at various distances $r_{\mathrm{M}}$ from the impact point is plotted as a function of time (only the first oscillation is shown).

It is worth noting that by increasing $r_{\mathrm{M}}$ the deflection of the plate is markedly delayed and the maximum deflection rapidly decreases. Note also that, with the obvious exception of locations close to the impacts, the initial displacement of the plate is directed upwards. This effect becomes more evident as $r_{M}$ increases.

The decrease in maximum deflection with $r_{\mathrm{M}}$ is also shown in Fig. 12, where the results are collected: two points are plotted for each impact in Fig. 12, since the deflection of the plate is evaluated for each impact at both point $\mathrm{A}$ and point B (see Fig. 5).

A further analysis of the results reveals a qualitative peculiarity of the observed behaviour close to the impact point (i.e. for $r_{M}$ smaller than stratum thickness): at these points, the recorded time histories are characterised by a noticeable asymmetry, where the initial downward deflection is more rapid than the following rebound. This point will be analysed in the following, by considering the acceleration of the plate and the distribution of stress increments acting on it.

The response of the structure in the direction perpendicular to the tunnel axis can be studied by considering similar impacts characterised by different $r_{\mathrm{t}}$. From the data plotted in Fig. 13, it is clear that the response of the structure in the transverse direction is almost immediate (no noticeable delay is observed), which is due to the stiffening effect of transversal girders.

\section{Plate acceleration}

In Fig. 14 the acceleration of the shelter roof recorded at various distances along the longitudinal axis $\left(r_{\mathrm{M}}\right)$ from the impact points is plotted against time (negative values correspond to downward acceleration). The larger accelerations are measured under the impact point, and nearby: the peak acceleration of the plate is as large as $-8 \boldsymbol{g}$ and $-6 \boldsymbol{g}$ at $r$ equal to 0 and $1.75 \mathrm{~m}$ respectively (negative values indicate downward acceleration). The peak acceleration decreases quite rapidly with $r_{\mathrm{M}}$, and is close to $-1 \boldsymbol{g}$ for $r_{\mathrm{M}}=3.5 \mathrm{~m}$. This value of acceleration represents a relevant threshold, as far as the interaction between the soil and the plate is concerned. In fact, $-1 \boldsymbol{g}$ is the acceleration that the soil would acquire if the plate was (hypothetically) suddenly removed. This means that a soil-plate detachment may occur if the (downward) acceleration of the plate is greater than $-1 \mathrm{~g}$. This occurrence plays a relevant role in the response of the structure, because the mass of the soil determines the oscillation period of the system. In this respect, the previously observed asymmetry of the plate deflection time histories (Figs 11(a), 11(b)) can be interpreted as the result of a temporary separation at the soil/structure interface. This point is discussed further in the next section.

\section{Soil-plate stresses}

In Fig. 15 the stress increments recorded at different values of $r_{\mathrm{M}}$ are plotted against time. These points are outside the load diffusion area, and therefore the stress increments are due entirely to the interaction between the soil and the oscillating plate. In agreement with the time

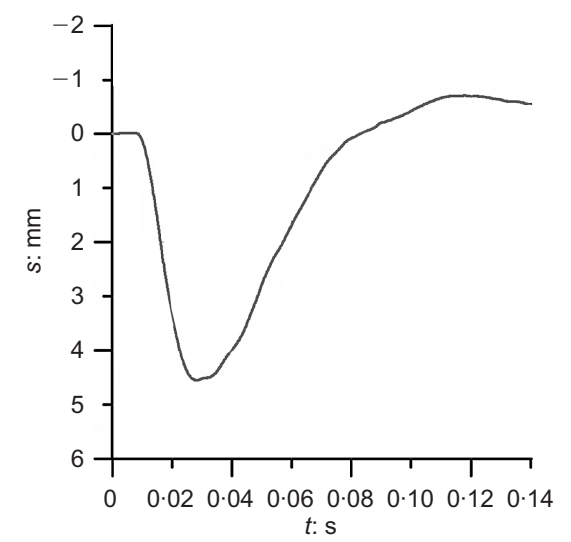

(a)

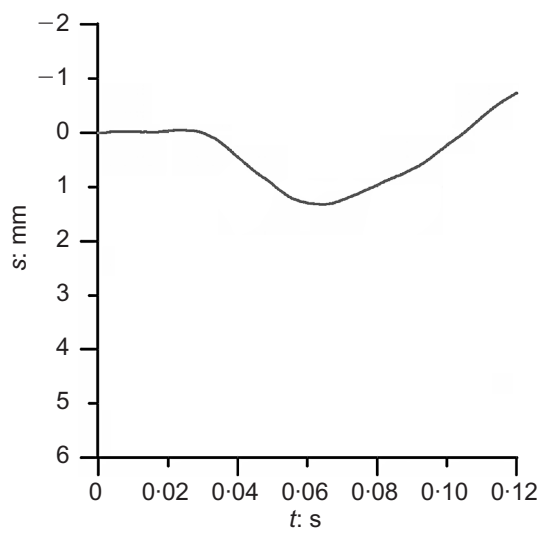

(d)

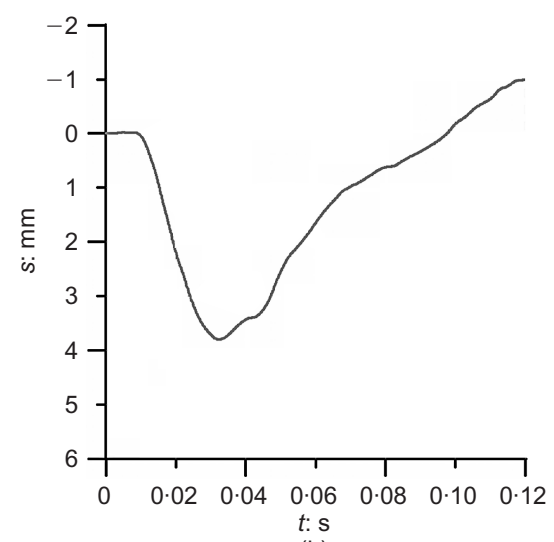

(b)

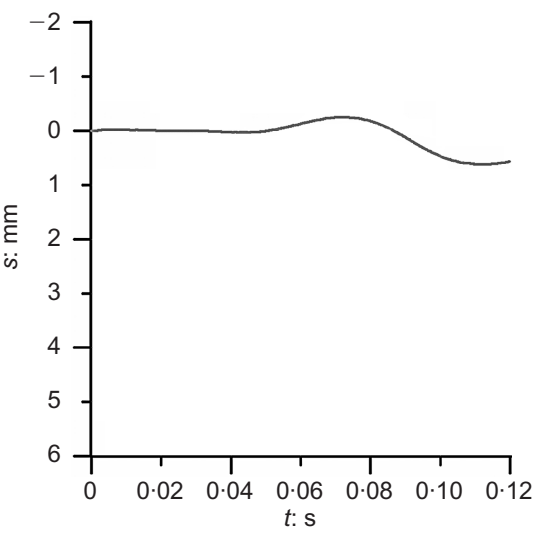

(e)

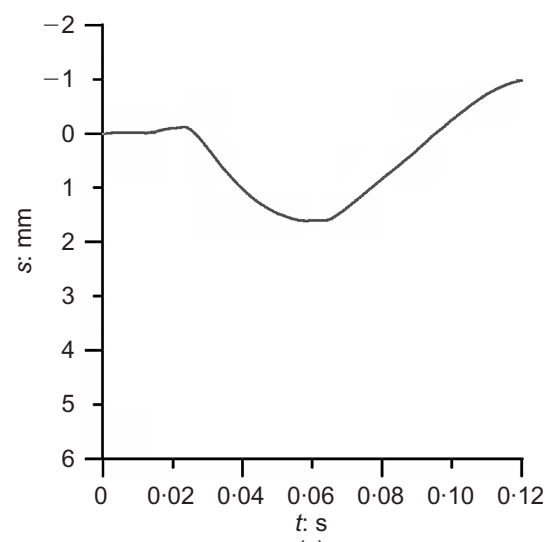

(c)

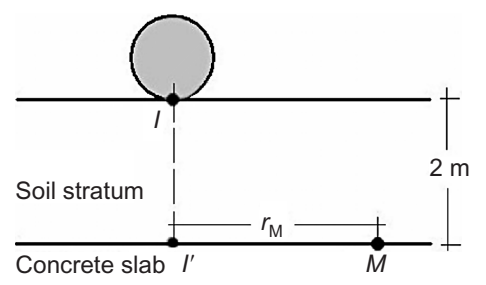

(f)

Fig. 11. Plate deflection against time, as recorded at: (a) $r_{\mathrm{M}}=0$; (b) $r_{\mathrm{M}}=1.75 \mathrm{~m}$; (c) $r_{\mathrm{M}}=3.5 \mathrm{~m}$; (d) $r_{\mathrm{M}}=5.25 \mathrm{~m}$; (e) $r_{\mathrm{M}}=10.5 \mathrm{~m}$. (f) Sketch of impact location (vertical section along tunnel axis) 


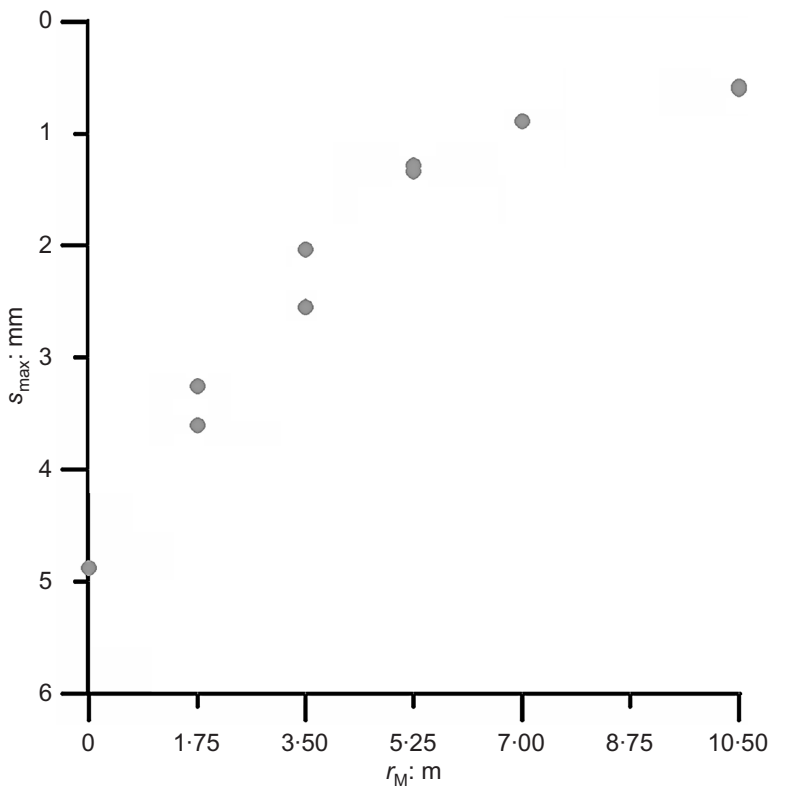

(a)

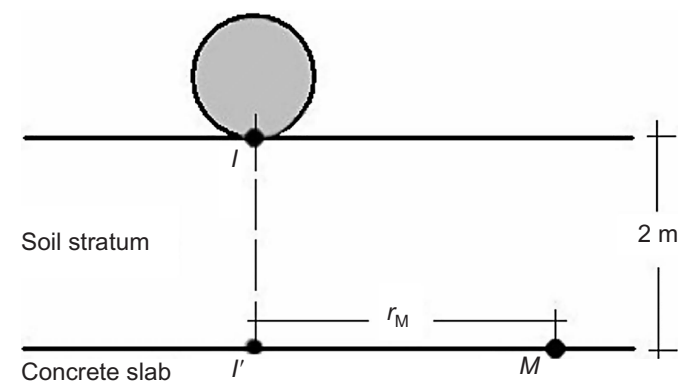

(b)

Fig. 12. (a) Maximum plate deflection as a function of $r_{M}$; (b) sketch of impact location (vertical section along tunnel axis)

evolution of plate displacements (Fig. 11), which was characterised by an initial upward movement followed by a more marked deflection, the stress increment is initially positive and then becomes negative. Noticeably, for $r_{\mathrm{M}}$ less than $5.25 \mathrm{~m}$, a negative stress increment as large as $30-40 \mathrm{kPa}$ is observed. Considering that the soil stratum is $2 \mathrm{~m}$ thick, and assuming a unit weight of the soil of $20 \mathrm{kN} / \mathrm{m}^{3}$, this reduction is close to balancing the initial stress, which means that a temporary separation between the soil and the plate is actually on the verge of occurring.
Dynamic amplification of structural response

Simplified design approaches in general assume that the structural response during an impact may be studied by means of a static equivalent analysis, where only the maximum value of impact actions is considered. This approach is actually oversimplified, and fails to reproduce some relevant features of the impact event, as will be shown in the following by comparing the results of tests 5 and 15 (see Table 2). The analysis of these two impacts is interesting, because the combination of different falling heights and soil compaction (impact 15 was performed without remoulding the crater created by a previous impact) gives rise to a similar trend in terms of stress increment recorded at the soil/plate interface. In particular, the maximum value of the stress increment is virtually the same, although the duration of the impulse is larger for impact 5 (Fig. 16(a)).

Despite very similar values of the maximum stress increment, the structural response is quite different: in fact, the plate deflection is noticeably larger under impact 5 . The two impacts took place at the same location (point A in Fig. 5), and therefore the observed difference cannot be ascribed to structural heterogeneity or to the influence of boundaries. Obviously, these results could not have been foreseen by adopting a static approach, which would consider only the maximum value of the stress increment; the observed structural response shows the influence of the impulse duration. To clarify this aspect, the dynamic structural response may be interpreted by employing a 1 DOF mass-spring model submitted to an impulse $I$

$$
I=\int_{0}^{t_{\mathrm{d}}} F(t) \mathrm{d} t
$$

where $t_{\mathrm{d}}$ is the impulse duration and $F(t)$ is the impulsive force. Following the approach illustrated in Chopra (1995), a dynamic factor can be introduced as follows

$$
R_{\mathrm{d}}=\frac{s_{\mathrm{d}}}{s_{0}}=\frac{s_{\mathrm{d}}}{F_{\max } / k}
$$

where $s_{\mathrm{d}}$ is the maximum displacement recorded during the oscillation, $F_{\max }$ is the maximum value of $F(t), k$ is the stiffness of the spring and $s_{0}$ is the reference displacement corresponding to the static application of $F_{\max }$.

According to Chopra (1995), the dynamic factor is a function of the ratio between the impulse duration, $t_{\mathrm{d}}$, and the natural oscillation period of the 1 DOF system, $T_{\mathrm{n}}$

$$
R_{\mathrm{d}}=R_{\mathrm{d}}\left(\frac{t_{\mathrm{d}}}{T_{\mathrm{n}}}\right)
$$

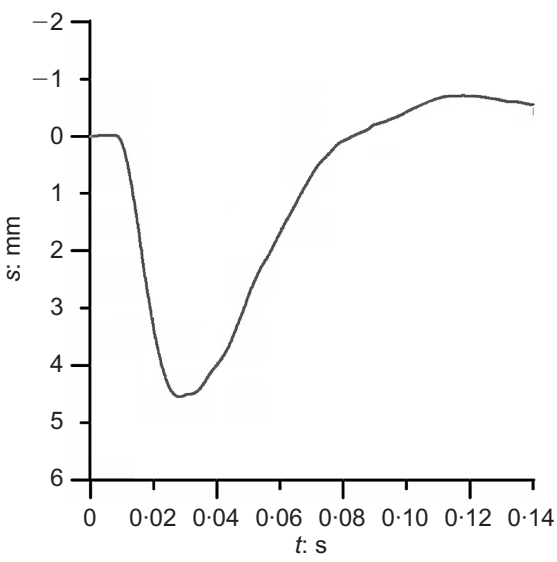

(a)

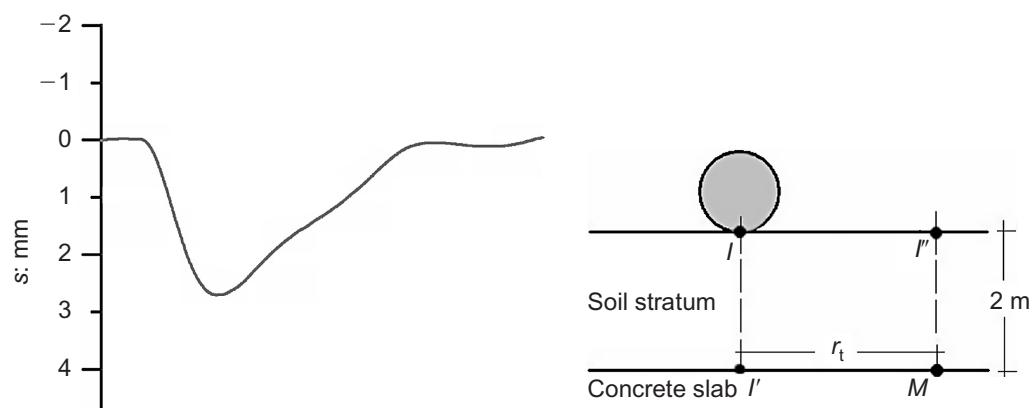

(c)

Fig. 13. Plate deflection against time, as recorded at: (a) $r_{\mathrm{t}}=0$; (b) $r_{\mathrm{t}}=2.75 \mathrm{~m}$. (c) Sketch of impact location (vertical section perpendicular to tunnel axis) 

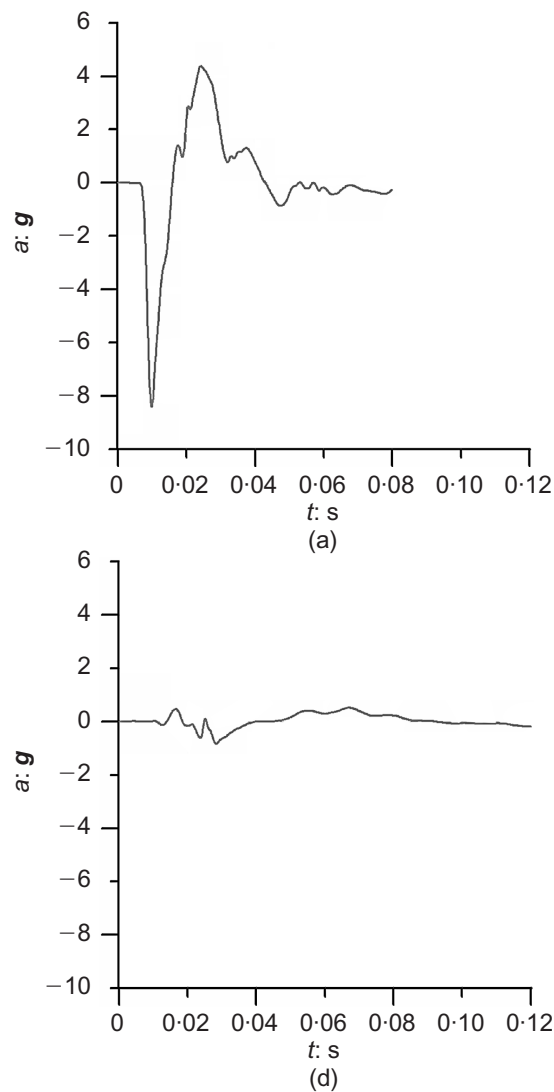

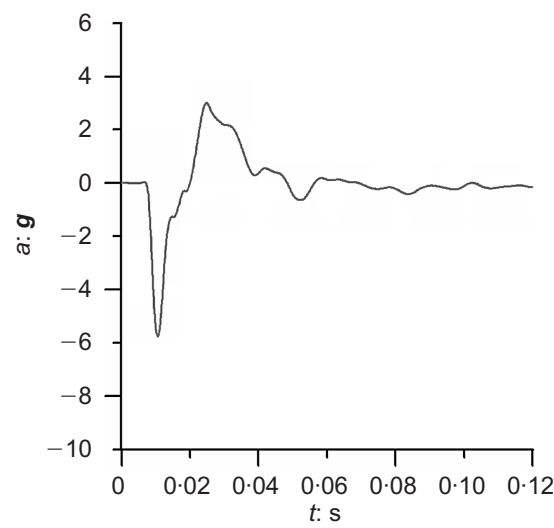

(b)

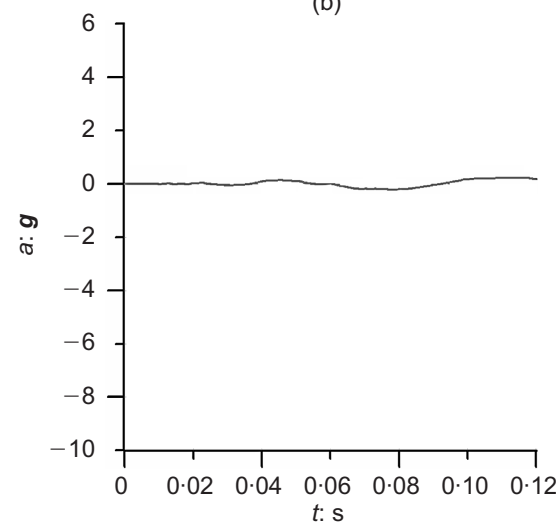

(e)

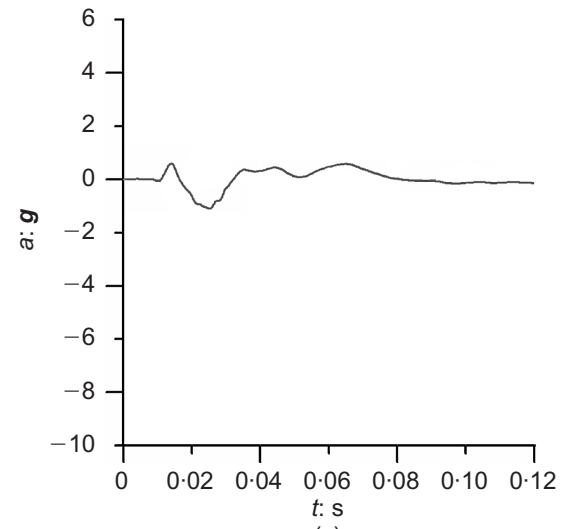

(c)

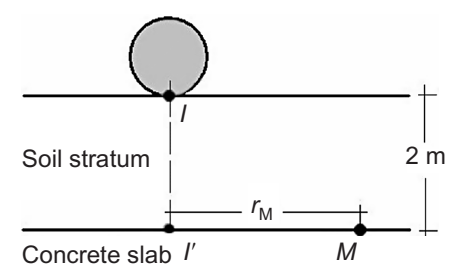

(f)

Fig. 14. Plate acceleration against time, as recorded at: (a) $r_{\mathrm{M}}=0$; (b) $r_{\mathrm{M}}=1.75 \mathrm{~m}$; (c) $r_{\mathrm{M}}=3.5 \mathrm{~m}$; (d) $r_{\mathrm{M}}=5.25 \mathrm{~m}$; (e) $r_{\mathrm{M}}=10.5 \mathrm{~m}$. (f) Sketch of impact location (vertical section along tunnel axis)

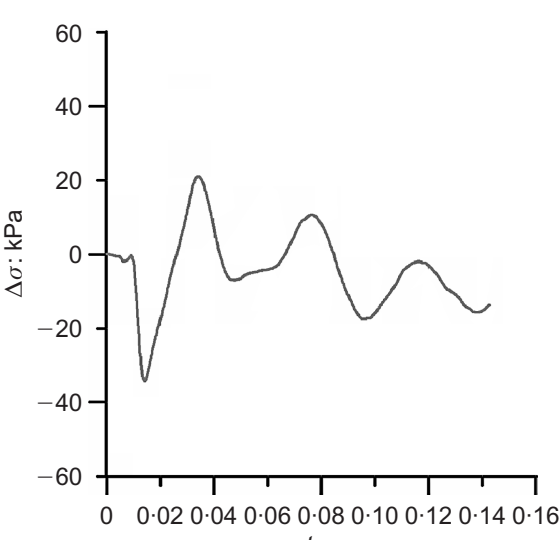

t: $\mathrm{s}$

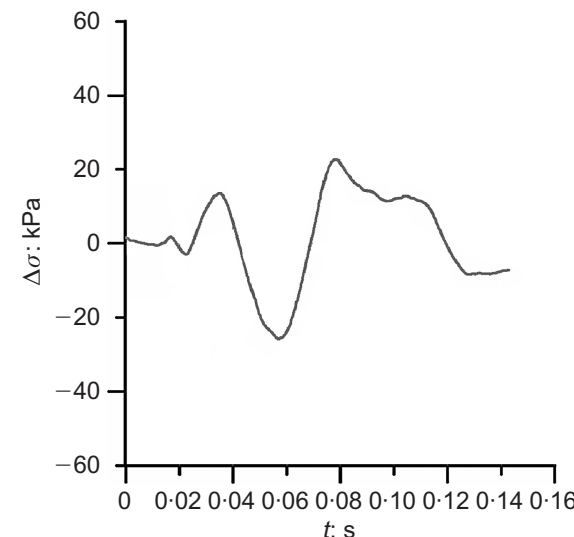

(d)

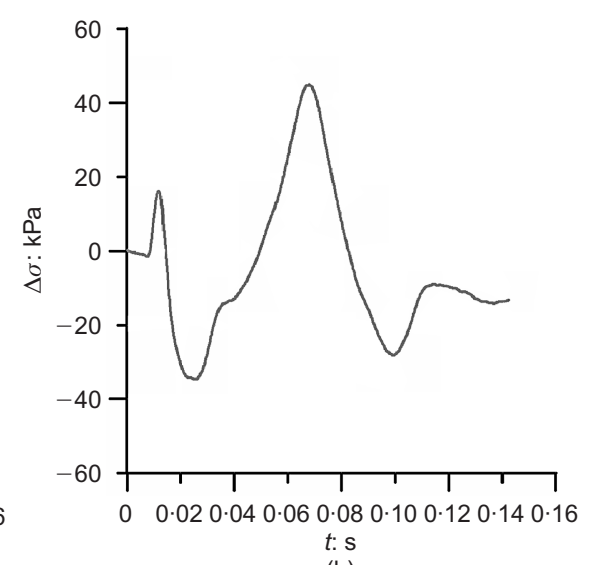

(b)

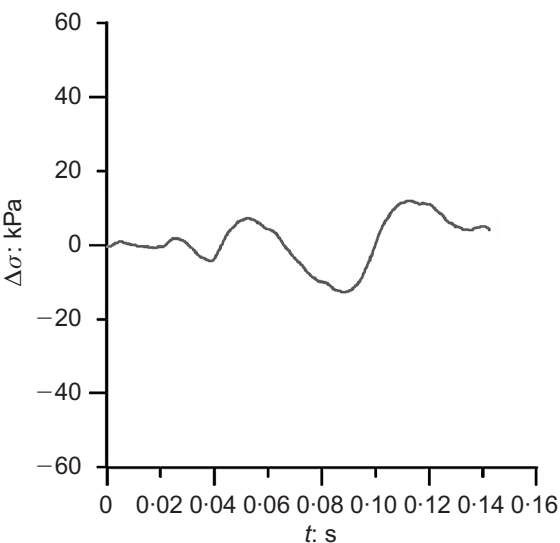

(e)

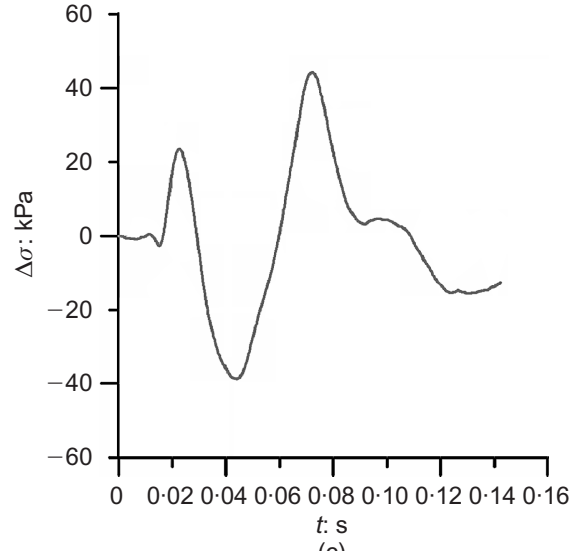

(c)

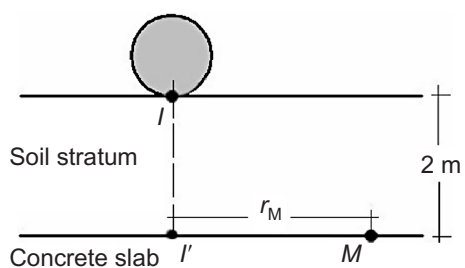

(f)

Fig. 15. Stress increments at soil-plate interface, as recorded at: (a) $r_{\mathrm{M}}=0$; (b) $r_{\mathrm{M}}=1.75 \mathrm{~m}$; (c) $r_{\mathrm{M}}=3.5 \mathrm{~m}$; (d) $r_{\mathrm{M}}=5.25 \mathrm{~m}$; (e) $r_{\mathrm{M}}=10.5 \mathrm{~m}$. (f) Sketch of impact location (vertical section along tunnel axis) 


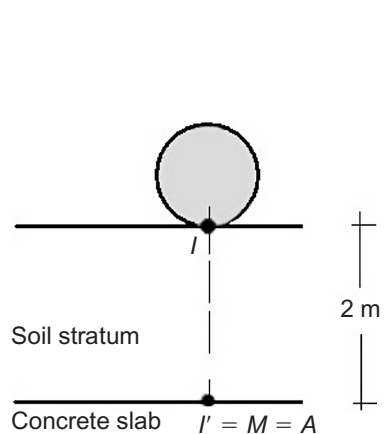

(a)

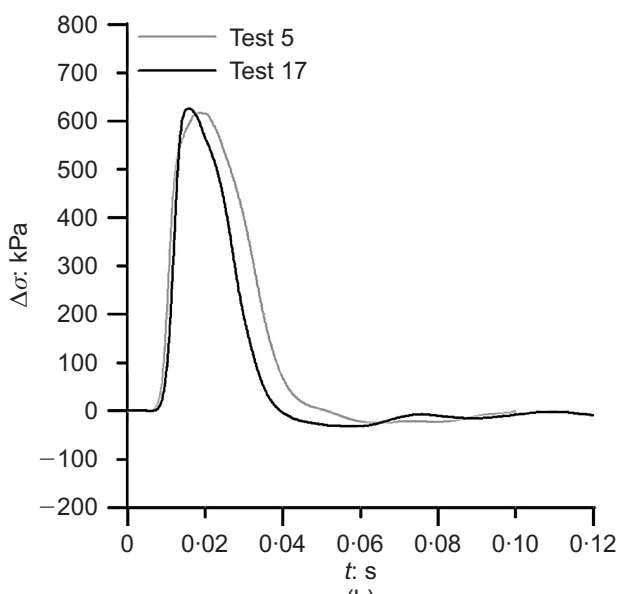

(b)

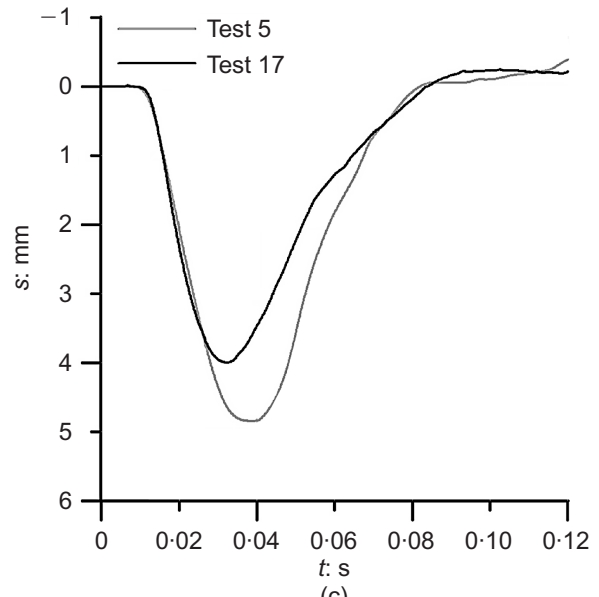

(c)

Fig. 16. Impacts 5 (virgin soil, $H=36 \cdot 4 \mathrm{~m}$ ) and 15 (compacted soil, $H=15 \mathrm{~m}$ ): (a) sketch of impact location (vertical section along tunnel axis); (b) vertical stress increment recorded at $I^{\prime}$ against $t$; (c) plate deflection at $I^{\prime}$ against $t$ (first oscillation)

with $R_{\mathrm{d}}$ increasing linearly with $t_{\mathrm{d}} / T_{\mathrm{n}}$, for $t_{\mathrm{d}} / T_{\mathrm{n}}<0 \cdot 5$. In the case under investigation, $t_{\mathrm{d}}$ is about $0.035 \mathrm{~s}$, and the natural oscillation period of the shelter, $T_{\mathrm{n}}$, is about $0.15 \mathrm{~s}$, as previously reported. Therefore, for the impacts under consideration, $t_{\mathrm{d}} / T_{\mathrm{n}} \approx 0 \cdot 25$, which is in agreement with the observed increase of the deflection with the time duration of the impulse.

\section{CONCLUSIONS}

In this paper, the results of real-scale rockfall impacts on sheltering tunnels were presented and commented upon, with the aim of highlighting the main features of the complex phenomenon under investigation. In parallel with the discussion of results, several suggestions regarding the requirements for an appropriate design approach were given.

Overall, the results are in good agreement with (limited) data reported in the literature with reference to small or reduced-scale impacts. In particular, the observed influence of falling height on the maximum impact force matches the trends reported in the literature. Similarly, a linear relation between the maximum values of the impact force, stress increment on the plate and plate deflection is observed. The comparison between the results of similar impacts performed on loose and dense soil strata shows clearly that the coefficients of the mentioned linear correlations are strongly dependent on the mechanical properties of the soil: this dependence, which would not appear (if not marginally) in static conditions, could be interpreted by introducing a dynamic amplification factor as a function of the soil stiffness.

The contemporary analysis of the three sublevels of the impact phenomenon (block-stratum impact; wave propagation, structural response) provides useful insight for the definition of an appropriate design approach. For typical impact situations an uncoupled approach could be adopted, where the impact force, the stress increment on the plate and the structural response are evaluated in sequence. Such an assumption disregards, for the sake of simplicity and conservatism, the backward influence of the plate deflection on the stress increment on the plate itself.

More insight into the soil-structure interaction mechanisms was provided by analysing the time evolution of the plate deflection and its influence on the contact stresses with the soil stratum outside the region of impact load diffusion. For the larger investigated falling height, the downward acceleration of the plate is so large that a temporary separation between the soil stratum and the plate is observed. This occurrence influences the period of oscillation of the structure, which in turn is very important in determining the structural response in dynamic conditions. Finally, the importance of a complete dynamic analysis for the shelter is stressed, by commenting on the influence of the impulse applied to the structure.

\section{ACKNOWLEDGEMENTS}

The experiments presented in this paper were performed in the framework of a long and fruitful collaboration between the authors and Ing. Sandro D'Agostini (Veneto Strade $\mathrm{SpA}$ ). The authors are grateful to him for the very stimulating and pleasant discussion, and for his contribution in keeping the research practically oriented. The financial support of Veneto Strade SpA is also acknowledged. Among the collaborators involved in the experimental campaign, the authors wish to thank Ing. Marco Secondi (Department of Structural Engineering, Politecnico di Milano), Ing. Andrea Milanese (Department of Aerospace Engineering, Politecnico di Milano) and Ing. Helenio Della Torre (Veneto Strade $\mathrm{SpA}$ ). The contribution of Professor Carmelo Gentile (Department of Structural Engineering, Politecnico di Milano) in characterising the dynamic properties of the structure is also acknowledged.

\section{NOTATION}

a plate acceleration

$C$ propagation velocity of stress wave

$D_{\mathrm{r}}$ relative density

$d_{\max }, d_{0}$ block penetration, reference block penetration

$E, E_{0}$ impact energy, reference impact energy

$H$ falling height

$F, F_{0}$ impact force, reference impact force

$F(t)$ impulsive force

$F_{\max }$ maximum value of impact force

$F_{1}$ impact force

$F_{2}$ resultant of stress increments on plate

$F_{3}$ support reaction

$I, I^{\prime}$ impact point, vertical projection of the impact point on the plate

$K$ stiffness parameter

$k$ stiffness of spring of 1 DOF system

$M$ measurement point

$M_{\mathrm{E}}$ soil stiffness as measured in a plate load test

$n$ stiffness parameter

$R_{\mathrm{d}}$ dynamic factor

$r_{\mathrm{A}}$ distance from point A along tunnel axis

$r_{\mathrm{B}}$ distance from point $\mathrm{B}$ along tunnel axis 
distance from point $\mathrm{M}$ along tunnel axis

$r_{\mathrm{t}}$ distance from tunnel axis

$s$ plate deflection

$s_{\mathrm{d}}$ maximum displacement during oscillation of $1 \mathrm{DOF}$ system

$s_{\max }$ maximum plate deflection

$s_{0} \quad$ static displacement

$T_{\mathrm{n}}$ natural oscillation period of $1 \mathrm{DOF}$ system

$t$ time

$t_{\mathrm{d}}$ impulse duration

$t_{0}$ impact time instant

$v$ boundary velocity

$\bar{v}$ boundary velocity at boundary stress peak

$\rho$ soil density

$\sigma$ boundary stress

$\bar{\sigma}$ maximum boundary stress

$\Delta \sigma_{\max }$ maximum stress increment on plate

$\Delta \sigma$ stress increment on plate

\section{REFERENCES}

ASTRA (2008). Einwirkungen infolge Steinschlags auf Schutzgalerien, issue V2.03. Bern, Switzerland: Swiss Federal Roads Office and Swiss Federal Railways.

Calvetti, F. (1998). Distinct element evaluation of the rock-fall design load for shelters. Riv. Ital. Geotec. 32, No. 3, 63-83.

Calvetti, F. \& di Prisco, C. (2007). Linee guida per la progettazione di gallerie paramassi. Brescia, Italy: Starrylink Editrice (in Italian).

Calvetti, F. \& di Prisco, C. (2009). An uncoupled approach for the design of rockfall protection tunnels. Struct. Engng Int. 19, No. 3, 342-347.

Calvetti, F. \& di Prisco, C. (2010). Une méthode de dimensionne- ment des galeries pare-pierres. In Géomécanique des instabilités rocheuses: Du déclenchement à l'ouvrage (eds S. Lambert and F. Nicot), pp. 335-367. Paris, France: Lavoisier (in French).

Calvetti, F. \& di Prisco, C. (2011). A new design method for rockfall shelters covered by granular layers. In Rockfall engineering (eds S. Lambert and F. Nicot), Chapter 10, pp. 343-373. Hoboken, NJ, USA: Wiley-ISTE.

Calvetti, F., di Prisco, C. \& Vecchiotti, M. (2005). Experimental and numerical study of rock-fall impacts on granular soils. Riv. Ital. Geotec. 39, No. 4, 95-109.

Chopra, A. K. (1995). Dynamics of structures: Theory and applications to earthquake engineering. Englewood Cliffs, NJ, USA: Prentice Hall.

di Prisco, C. \& Vecchiotti, M. (2006). A rheological model for the description of block impacts on granular strata. Géotechnique $\mathbf{5 6}$, No. 7, 469-482, http://dx.doi.org/10.1680/geot.2006.56.7.469.

Janbu, N. (1963). Soil compressibility as determined by oedometer and triaxial tests. Proc. 3rd Eur. Conf. Soil Mech. Found. Engng, Wiesbaden 1, 19-25.

JRA (2000). Manual for anti-impact structures against falling rocks. Tokyo: Japan Road Association (in Japanese).

Labiouse, V., Descoeudres, F., Montani, S. \& Schmidhalter, C. A (1994). Etude expérimentale de la chute de blocs rocheux sur une dalle en beton armé recouverte per des matériaux amortissants. Rév. Fr. Géotech. 69, No. 4, 41-62 (in French).

Labiouse, V., Descoudres, F. \& Montani, S. (1996). Experimental study of rock sheds impacted by rock blocks. Struct. Engng Int. 3, No. 1, 171-175.

Schellenberg, K. \& Vogel, T. (2009). A dynamic design method for rockfall protection galleries. Struct. Engng Int. 19, No. 3, 321326.

Stupazzini, M. \& Zambelli, C. (2005). GeoELSEvp: a spectral element approach for dynamic elasto-viscoplastic problems. Riv. Ital. Geotec. 39, No. 4, 70-82. 